\title{
Ruptured Spinal Dermoid Cyst
}

\author{
Gokhan Kuyumcu, Miral Jhaveri
}

Keywords: Spinal canal, trauma, dermoid cyst, emergency

doi:10.1017/cjn.2017.26

Can J Neurol Sci. 2017; 44: 601-602

A 28-year-old patient presented with sudden onset bilateral leg paresthesia and left-sided lower extremity muscle weakness. Spinal magnetic resonance imaging (MRI) revealed a heterogeneous T1-hyperintense nonenhancing, intradural extramedullary mass intimately associated with the conus medullaris (Figure 1A, B). No lumbar dermal sinus or hair tuft was appreciable on physical examination and no sign of dysraphism was appreciable with MRI.
Additional punctate $\mathrm{T} 1$ hyperintensities consistent with fat droplets were noted in the central canal (Figure 1C, D), leading to the diagnosis of a ruptured dermoid cyst. Fat droplets in the central canal or subarachnoid space are most common findings of ruptured spinal dermoid cysts in MRI or computed tomography (CT). Any change in the volume and composition of previously diagnosed intraspinal dermoid cyst is also a main finding of rupture. ${ }^{1}$
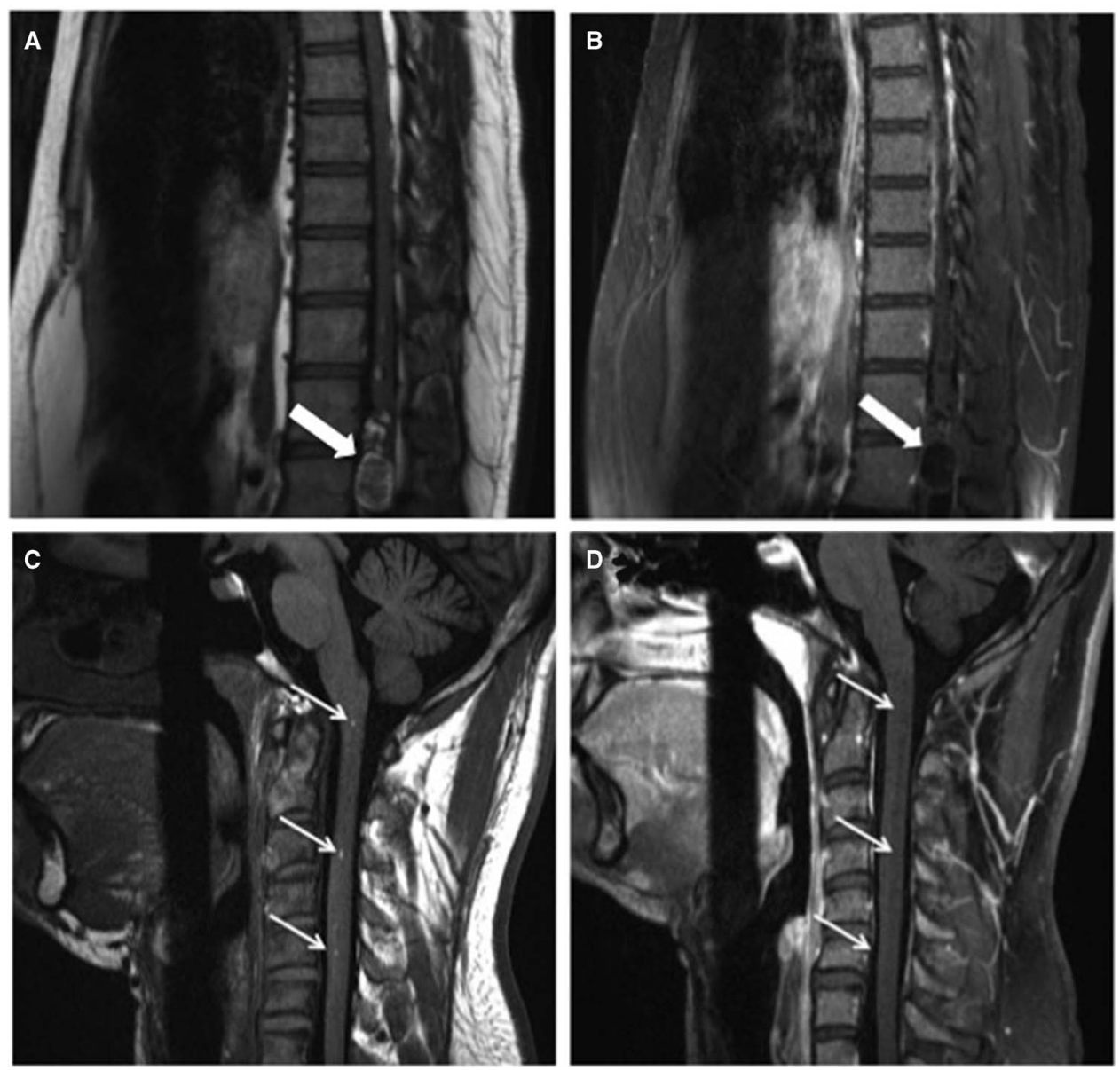

Figure 1: (A, B) Sagittal pre- and postcontrast T1-weighted MRI scan of the spine showing a heterogeneous, T1-hyperintense mass diagnosed as spinal dermoid. No enhancement is appreciable. (C) Cervical T1-weighted image showing fat droplets extending to the level of medulla. (D) T1-weighted fatsuppressed images with contrast showing suppression of fat droplets. 
Dermoid cyst in the central nervous system is generally recognized by demonstration of associated fat on imaging, which is relatively easy on CT scans. On MRI, dermoid cysts are generally hyperintense on $\mathrm{T} 1$; the suppression of signal on fat-suppressed sequences confirms the diagnosis. Dissemination of T1-hyperintense fat droplets in the subarachnoid space following rupture is characteristic. Small lesions or lesions with high fluid content may pose a diagnostic challenge because of low $\mathrm{T} 1$ signal intensity and no appreciable fat on CT because of volume averaging.

Spinal dermoid cysts are rare benign spinal masses composed of embryological skin and its appendages. They can be associated with defective neural tube closure, spinal dysraphism, and a dermal sinus tract. They are generally asymptomatic and discovered incidentally in patients younger than 20 years old. Males and females are affected equally. ${ }^{2}$ Rupture of a spinal dermoid is an emergency and early recognition and surgical intervention can decrease morbidity and mortality. Spillage of dermoid contents into the subarachnoid space may result in aseptic chemical meningitis with profound irritative effects presumably secondary to fatty acids. ${ }^{3}$ The goal of surgery is evacuation of the cyst contents with special care to avoid release of fatty elements in the subarachnoid space. The spinal dermoid cyst wall is usually tightly adherent to neural structures, and attempts at complete resection may lead to permanent neurologic damage. ${ }^{2,3}$

\section{Disclosures}

The authors do not have anything to disclose.

\section{STATEMENT OF AUTHORSHIP}

GK drafted the article and had final approval of the last version. MJ undertook conception, design, and final approval of the last version.

\section{REFERENCES}

1. Karadag D, Karagulle AT, Erden A, Erden I. MR imaging of a ruptured intraspinal dermoid tumour with fat droplets in the central spinal canal. Australas Radiol. 2002;46:444-6.

2. Sanaullah M, Mumtaz S, Memon AA, Hashim AS, Bashir S. Intramedullary dermoid cyst with relatively atypical symptoms: a case report and review of the literature. J Med case Rep. 2013;7:104.

3. Girishan S, Rajshekhar V. Rapid-onset paraparesis and quadriparesis in patients with intramedullary spinal dermoid cysts: report of 10 cases. J Neurosurg Pediatr. 2015:1-8. 